\title{
Food for High-Altitude Expeditions: Pugh Got It Right in 1954-A Commentary on the Report by L.G.C.E. Pugh: "Himalayan Rations With Special Reference to the 1953 Expedition to Mount Everest"
}

\author{
E. Wayne Askew, PhD \\ From Division of Foods and Nutrition, University of Utah, 210 N-HPR, Salt Lake City, UT
}

Few scholarly discussions of high-altitude physiology would be complete without reference to the work and writings of L.G.C.E. Pugh. Pugh was a physician, an avid outdoorsman, and a perceptive scientist (a "salty dog" in Wilderness Medical Society former President Blair Erb's terminology). Pugh clearly had some strong opinions about the role of diet and its relationship to performance at altitude garnered from first-hand observations. Ironically, many of his conclusions on nutrition, if presented for publication to journals today, perhaps might be found a bit "anecdotal" and lacking in databased "rigor" to substantiate some of his claims. However, a careful examination of his conclusions and a comparison to developments during the ensuing 50 years lead the modern nutrition scientist to conclude that Pugh's conclusions and recommendations are, with few exceptions, as valid today as they were 50 years ago when he first published "Himalayan Rations with Special Reference to the 1953 Expedition to Mount Everest." 1

Perhaps a bit of Pugh's historical background, courtesy of the Register of the L.G.C.E. Pugh Papers maintained by the Mandeville Special Collections Library of the University of California, San Diego, ${ }^{2}$ might help the reader gain an appreciation of Pugh's ability to make first-hand field observations and translate them into useful scientific information:

Lewis Griffith Cresswell Evans Pugh was born on October 19, 1909, in Shrewsbury, UK. He studied medicine at Oxford University and obtained his medical degree in 1939. L.G.C.E. Pugh was a British physiologist and mountaineer who combined field and laboratory research in pioneering work in high-altitude physiology and

Direct correspondence to Division of Foods and Nutrition, University of Utah, 210 N-HPR, Salt Lake City, UT 84112 (e-mail: wayne. askew@health.utah.edu). sports medicine from 1940 to 1986 . He joined the British Army as a medical officer at the start of World War II and, in 1943, was sent to the Mountain Warfare Training Center in Lebanon to select, train, and evaluate the fitness of ski troops. There, he began a career of research into the physiologic effects of altitude, temperature, and exertion. At the end of the war, Pugh was studying rheumatology and cardiology in the UK at the British Postgraduate Medical School, London, but was interrupted in 1947 by an invitation from the British Navy to accompany a voyage to the Arctic. This expedition brought him back to field physiology and the study of human responses to cold. In 1950, Pugh joined the Medical Research Council's new Division in Human Physiology, set up to study the effects of extreme environments. Pugh is especially remembered for his studies during the 1952 British Himalayan Expedition to Mt Cho Oyu, the 1953 British Himalayan Expedition to Mt Everest, the 196061 Himalayan Scientific and Mountaineering Expedition to Mt Everest, and the 1957-58 Trans-Antarctic Expedition. Pugh was the lead scientist on the Cho Oyu expedition and, with Edmund Hillary, co-led the 1960-61 Himalayan Scientific and Mountaineering Expedition ("Silver Hut"), which spent 5 months at 19000 feet or higher near Mt Everest. Pugh was a true "environmental physiologist" with interests in altitude, thermal physiology, and exertion. Pugh obtained data on Mt Cho Oyu that demonstrated the critical importance of adequate hydration and oxygen, findings that were crucial to the first successful climb of Mt Everest in 1953.

The data he collected from the Cho Oyu climbers indicated that adequate hydration and nutrition were important factors and that the oxygen equipment and clothing used by earlier expeditions had not been optimally designed. His work on hydration, nutrition, oxygen flow rates, and protective clothing addressed many of the 
practical problems of high-altitude activity and contributed to the success of the 1953 British expedition to Mt Everest. Pugh had helped plan and outfit the expedition, participated as the lead scientist and physician, and became part of the group of scientists-Bruno Balke, R. B. and T. B. Bourdillon, David Bruce Dill, Charles Houston, Ulrich Luft, Nello Pace, Michael Ward, and John West - that established modern high-altitude physiology.

In 1957, Pugh took part, with Nello Pace, in the first Trans-Antarctic Expedition, visiting Scott Base and the South Pole. He studied cold stress and the effects of solar radiation on humans and the adaptive mechanisms of seals. In 1960, he headed the scientific team on the Himalayan Scientific and Mountaineering Expedition, led by Edmund Hillary. This expedition became known as the Silver Hut Expedition, named for the laboratory set up on the Ming Bo glacier at 19000 feet. Researchers spent 5 months investigating the physiology of exertion and levels of respiratory oxygen. Pugh died on December 22, 1994, leaving a legacy of pioneering environmental physiology research.

It was Pugh's observations from the 1953 expedition to Mt Everest ${ }^{1}$ and subsequent speculation that eventually led the US Army Medical Research and Nutrition Laboratory, under the direction of Frank Constario, to test a high-carbohydrate diet for performance at altitude on Pikes Peak in 1969. ${ }^{3}$ Pugh and Consolazio's work led to further investigations of the benefits of carbohydrates $^{4,5}$ and subsequent field studies of a high-carbohydrate diet at the summit of Mauna Kea in $1985 .{ }^{6}$ Research on the attributes of carbohydrates at altitude continues to be the subject of recent investigations. ${ }^{7-9}$ The benefits of carbohydrates (with respect to performance) alluded to by Pugh were largely substantiated by the Pikes Peak and Mauna Kea study; however, Pugh's insistence that carbohydrates were "preferred or craved" at altitude has not subsequently been corroborated. Indeed, Operation Everest II, although not a field study but a carefully controlled laboratory hypobaric chamber study, gave no indication that the desire for carbohydrates increased with altitude. ${ }^{10}$ Subsequent field studies on Everest have even presented an opposite conclusion; fatty items may even sometimes be favored by climbers. ${ }^{8}$ Other studies have not found significant attributes attributable to carbohydrates at altitude, ${ }^{7}$ despite theoretical considerations of the metabolic advantages of carbohydrates. Nevertheless, Pugh should be credited with recognizing and emphasizing the importance of nutrition and hydration at altitude. Subsequent studies by other investigators have led to similar conclusions regarding nutrition and hydration at altitude. ${ }^{11-14}$ As a footnote, although Pugh and others often receive credit for the statement that carbohydrate consumption can reduce the "felt" altitude because of oxygen efficiencies associated with its oxidative state, it should be remembered that Pugh credited the 1947 paper by Houston ${ }^{15}$ in the Journal of Aviation Medicine for this observation.

Some of the main points related to nutrition from Pugh's 1954 paper $^{1}$ and some editorial comments by this reviewer are as follows:

"During a period at high altitude there was a marked reduction in appetite ... the average weight loss over the initial 24 day period. . ranged from 6-14 pounds."

This observation has been corroborated numerous times since 1954. Weight loss at altitude is a common occurrence, except when constant focus is given to maintaining caloric balance at altitude. ${ }^{16}$

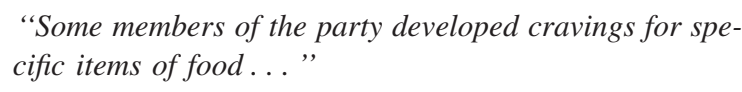

Variable results have been recorded concerning "cravings" at altitude, and most are anecdotal. The desire for more carbohydrates may be related to the degree of glycogen depletion experienced. No solid experimentalbased evidence exists to corroborate this statement. ${ }^{10}$

"The low food intake on Cho Oyu was regarded as evidence of insufficient acclimatization to altitude."

Anorexia usually accompanies altitude illness; hence, low food intake is a consequence of "insufficient acclimatization to altitude" or is at least a secondary response to altitude illness. ${ }^{17,18}$

"The caloric value of the composite ration ... was approximately $4800 \mathrm{Cal} / \mathrm{man}$ daily."

Modern energy expenditure studies with doubly labeled water have arrived at similar magnitudes of energy expenditure rates for work at moderate-to-high altitude. ${ }^{13,19}$

A further question which requires to be raised is that vitamin requirements, which might be inadequate for a party subsisting for 3 months on packed rations. In the 1953 expedition . . . each climber was issued . . . vitamin tablets containing ascorbic acid $75 \mathrm{mg}$, vitamin A 500IU, vitamin D 500IU, thiamine $3.0 \mathrm{mg}$, riboflavin $2.0 \mathrm{mg}$, nicotinamide $20.0 \mathrm{mg}$, folic acid $1.0 \mathrm{mg}$ and vitamin $B_{12} 1$ $\mu g$.

Food technology has progressed in the intervening 50 years to the point that packaged rations can be adequately fortified with vitamins and minerals that are stable for prolonged periods. Pugh's recommendation was probably prudent advice in 1953, and multivitamin supplementation is still good "insurance" against suboptimal or sporadic food intake on expeditions today. Noting that 
Pugh recommended only $75 \mathrm{mg}$ of vitamin $\mathrm{C}$ and no supplemental vitamin E, we would probably put greater emphasis on the antioxidant vitamins in today's vitamin supplement mixture for work at altitude, with intakes in the range of 250 to $2000 \mathrm{mg}$ of vitamin $\mathrm{C}$ and 400 to $1000 \mathrm{mg}$ of $\alpha$-tocopherol. ${ }^{20,21}$

"On expeditions to high difficult mountains the extra ex-
pense of taking composite rations is fully justified..."

This was an important advance in both logistics and nutrition in 1953. Easy-to-prepare food that does not require a great deal of thought or preparation is essential at high altitude. Few would take issue with Pugh on this note.

"Insufficient intake of food, especially in combination with fluid deficiency, leads to deterioration in performance if continued for more than 1 or 2 days."

This observation has been repeatedly confirmed in a multitude of environments but is especially noticeable at altitude, where anorexia combines with exertion to deplete energy reserves. ${ }^{22}$

"Even men who at sea level are not fond of sugar and sweets find that their sugar intake increases as they go higher."

Once again, this observation has not been convincingly documented, although most altitude physiologists and nutritionists agree that carbohydrate intake is especially important with respect to avoiding glycogen depletion. ${ }^{10}$

"Climbers living at altitudes above 19,000 ft usually consume about $12 \mathrm{oz}$. sugar a day and a large proportion of their food takes the form of sugar dissolved in beverages.",

This advantage of carbohydrates may be more a function of ease of ingestion and preparation of food than any actual "requirement." The desire and capability to drink often exceed the appetite for and desire to prepare food, so for short periods at extreme altitude, sweetened beverages have proven to be an effective, viable avenue for energy ingestion.

"The increased appetite for sugar at high altitude has a physiological justification in terms of respiration."

"Increased appetite" aside, carbohydrates are energetically more efficient under low oxygen pressure because of the amount of oxygen associated with its carbon molecules. The carbon dioxide produced while oxidizing carbohydrates is greater than for a similar amount of fat or protein. This increased carbon dioxide dissolved in the circulating blood can help stimulate the respiratory drive and subsequent oxygenation at altitude.
"It was of great interest, therefore, to find that on Everest body-weight was so much better maintained by more careful acclimatization and improvement of diet."

Pugh's focus of attention on the maintenance of body weight was and still is very approprieate. Body weight is easily monitered and helps to determine adequate fluid and energy intake balances without sophisticated instrumentation. ${ }^{16}$ Pugh was aware that this seemingly simple goal is difficult to achieve in practice and that the climber requires constant reminders to eat and drink.

\section{Summary}

An examination of the nutritional recommendations at altitude by L.G.C.E. Pugh made in the early 1950s reveals that his approaches to feeding and hydration at altitude are still ascribed to today, 50 years later. We can forgive his one perhaps overstatement concerning the "craving" for carbohydrates at altitude if we simply acknowledge that he was generally correct about the benefits of carbohydrates for work at altitude. Pugh's emphasis on adequate energy intake and fluid intake at altitude is as sound today as it was in 1954.

\section{References}

1. Pugh LGC. Himalayan rations with special reference to the 1953 expedition to Mount Everest. Proc Nutr Soc. 1954;13:60-69.

2. Register of L.G.C.E. Pugh Papers 1940-1986. MSS 0491 Mandeville Special Collections Library, University of California, San Diego. Available at: http://orpheus.ucsd.edu/ speccoll/testing/html/mss0491a.html. Sources cited within this register: The Times (London), January 7, 1995; Hypoxia Symposium, J. R. Sutton, et al, eds., 1993; West J, High Life: A History of High-Altitude Physiology and Medicine, 1998.

3. Consolazio CF, Matoush LO, Johnson HL, Krywicki HJ, Daws TA, Issac GJ. Effects of high carbohydrate diets on performance and clinical symptomatology after rapid ascent to high altitude. Fed Proc. 1969;28:937-943.

4. Hansen JE, Hartley LH, Hogan RP. Arterial oxygen increased by high carbohydrate diet at altitude. J Appl Physiol. 1972;33:441.

5. Dramise JG, Inouye CM, Christensen BM, Fults RD, Canham JE, Consolazio CF. Effects of a glucose meal on human pulmonary function at 1600 and $4300 \mathrm{~m}$ altitudes. Aviat Space Environ Med. 1975;46:365-368.

6. Askew EW, Claybaugh JR, Hashiro GM, Stokes WS, Sato A, Cucinell SA. Mauna Kea III: Metabolic Effects of Dietary Carbohydrate Supplementation During Exercise at 4100 M Altitude. Washington, DC: US Army Research Institute of Environmental Medicine; 1984. US Army Research Institute of Environmental Medicine technical report T12-87. 
7. Swenson ER, MacDonald A, Vatheuer M, et al. Acute mountain sickness is not altered by a high carbohydrate diet nor associated with elevated circulating cytokines. Aviat Space Environ Med. 1997;68:499-503.

8. Reynolds RD, Licktieg JA, Howard MP, Deuster PA. Intakes of high fat and high carbohydrate foods by humans increased with exposure to increasing altitude during an expedition to Mt Everest. J Nutr. 1998;128:50-55.

9. Lawless NP, Dillard TA, Torrington KG, Davis Q, Kammimori G. Improvement in hypoxemia at 4600 meters of simulated altitude with carbohydrate ingestion. Aviat Space Environ Med. 1999;70:874-877.

10. Rose MS, Houston CS, Fulco CS, Coates G, Sutton JR, Cymerman A. Operation Everest II: nutrition and body composition. J Appl Physiol. 1984;57:1580-1585.

11. Butterfield GE, Gates J, Brooks GA, et al. Energy balance and weight loss during three weeks at $4,300 \mathrm{~m}$. J Appl Physiol. 1992;72:1741-1748.

12. Edwards JSA, Askew EW, King N, Fulco CS. Nutritional intake and carbohydrate supplementation at high altitude. J Wilderness Med. 1994;5:20-33.

13. Askew EW. Environmental and physical stress and nutrient requirements. Am J Clin Nutr. 1995;61:631S-637S.

14. Reynolds RD, Lickteig JA, Deuster PA, et al. Energy metabolism increases and regional body fat decreases while regional muscle mass is spared in humans climbing Mt. Everest $J$ Nutr. 1999;129:1307-1314.
15. Houston CS. Adaptations which produce acclimation of oxygen lack. J Aviat Med. 1947;8:237.

16. Butterfield GE, Gates J, Fleming S, Brooks GA, Sutton JR, Reeves JT. Increased energy intakes minimize weight loss in men at high altitude. J Appl Physiol. 1992;72: 1741-1748.

17. Bailey DM, Davies B, Milledge JS, et al. Elevated plasma cholecystokinin at high altitude: metabolic implications for the anorexia of acute mountain sickness. High Altitude Med Biol. 2000;1:9-23.

18. Roach RC, Hackett PH. Frontiers of hypoxia research: acute mountain sickness. J Expl Biol. 2001;204:31613170 .

19. Hoyt RW, Jones TE, Baker-Fulco CJ, et al. Doubly labeled water measurement of human energy expenditure during exercise at high altitude. Am J Physiol. 1994;266:R966R971.

20. Askew EW. Work at high altitude and oxidative stress: antioxidant nutrients. Toxicology. 2002;180:107-119.

21. Dietary Reference Intakes for Vitamin C, Vitamin E, Selenium and Carotenoids. Washington, DC: National Academy Press; 2000.

22. Brooks GA, Butterfield GA. Metabolic responses of lowlanders to high-altitude exposure. Malnutrition versus the effects of hypoxia. In: Hornbein TF, Schoene RB, eds. High Altitude: An Exploration of Human Adaptation. New York, NY: Marcel Dekker; 2001:569-599. 